Pure Appl. Chem., Vol. 73, No. 2, pp. 295-298, 2001.

(C) 2001 IUPAC

\title{
Novel coordination behavior of unsaturated hydrocarbon ligands on Pd-Pd bonds*
}

\author{
Hideo Kurosawa ${ }^{\dagger}$ and Tetsuro Murahashi \\ Department of Applied Chemistry, Osaka University, Suita, Osaka 565-0871, \\ Japan
}

Abstract: The dinuclear $\mathrm{Pd}(\mathrm{I})$ complexes containing substitutionally labile acetonitrile ligands $\left[\mathrm{Pd}_{2}\left(\mathrm{CH}_{3} \mathrm{CN}\right)_{2}(\mathrm{~L})_{2}\right]\left(\mathrm{BF}_{4}\right)_{2}\left[\mathrm{~L}=\mathrm{CH}_{3} \mathrm{CN}(\mathbf{1}), \mathrm{PPh}_{3}(\mathbf{2})\right]$ were prepared. The complex 1 was demonstrated to serve as a versatile building block for synthesizing sandwich chain complexes made of conjugated polyenes and linear polypalladium chains. The complex 2 reacted with 2 equiv arylacetylenes to give dinuclear organopalladium complexes arising from formal $[2 \sigma+2 \pi+2 \pi]$ addition with the Pd-Pd $\sigma$ bond participating as one component. The reaction of 2 with 1,3-butadiene afforded a complex regarded as an intermediate lying halfway on the $[2 \sigma+4 \pi]$ reaction coordinate.

\section{INTRODUCTION}

In contrast to extensively developed chemistry of mononuclear organopalladium complexes, only a very limited knowledge has been accumulated on the organometallic complexes containing the discrete $\mathrm{Pd}-\mathrm{Pd}$ bond. This may partly be attributed to paucity of any Pd-Pd bonded complexes as starting reagents which ought to be easy to access and yet sufficiently reactive to common organic ligands such as olefins and acetylenes. We undertook synthesis and reactions of dinuclear $\operatorname{Pd}(\mathrm{I})$ complexes containing multiple labile ligands.

\section{SYNTHESIS OF ACETONITRILE PD(I)-PD(I) COMPLEXES}

The $\mathrm{Pd}(\mathrm{II})$ complex $\left[\mathrm{Pd}\left(\mathrm{CH}_{3} \mathrm{CN}\right)_{4}\right]\left(\mathrm{BF}_{4}\right)_{2}$ has long been recognized as the versatile source of active catalysts or organopalladium compounds [1]. We found [2,3] that treatment of $\left[\mathrm{Pd}\left(\mathrm{CH}_{3} \mathrm{CN}\right)_{4}\right]^{2+}$, or $\left[\mathrm{Pd}\left(\mathrm{CH}_{3} \mathrm{CN}\right)_{2}\left(\mathrm{PPh}_{3}\right)_{2}\right]^{2+}$ derived therefrom, with 1 equiv $\mathrm{Pd}_{2}(\mathrm{dba})_{3}$ in acetonitrile gave $\left[\mathrm{Pd}_{2}\left(\mathrm{CH}_{3} \mathrm{CN}\right)_{4}(\mathrm{~L})_{2}\right]^{2+}\left[\mathrm{L}=\mathrm{CH}_{3} \mathrm{CN}(\mathbf{1}), \mathrm{PPh}_{3}(\mathbf{2})\right]$ in good yields (eq. 1). The X-ray analysis showed the structure of $\mathbf{2}$ as indicated [4]. Two acetonitrile ligands of $\mathbf{2}$ readily dissociated in $\mathrm{CH}_{2} \mathrm{Cl}_{2}$ solution to give a crystalline product of which the $\mathrm{X}$-ray structure determination revealed the $\mathrm{PPh}_{3}$ bridging dinuclear structure (eq. 2) [5].

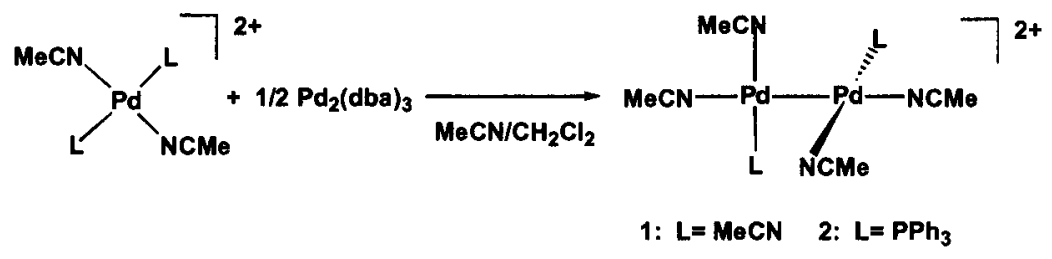

\footnotetext{
*Lecture presented at the XIX ${ }^{\text {th }}$ International Conference on Organometallic Chemistry (XIX ICOMC), Shanghai, China, 23-28 July 2000. Other presentations are published in this issue, pp. 205-376.

†Corresponding author
} 
2

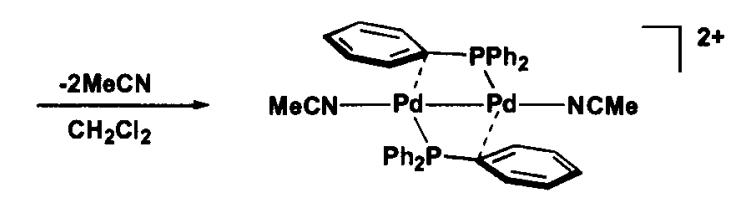

The coordination of the ipso carbon of the $\mathrm{PPh}_{3}$ ligand is deduced to be maintained also in solution, since ${ }^{13} \mathrm{C}$ NMR spectra clearly showed two distinct phenyl carbon resonances for the Pd-bound and free rings $(1: 2)$ at $-90{ }^{\circ} \mathrm{C}$. These two groups of resonances coalesced at the higher temperatures, suggesting rapid dissociation of the $\mathrm{Pd}-\mathrm{C}$ bond followed by rotation about the $\mathrm{Pd}-\mathrm{P}$ bond.

\section{REACTION OF 2 WITH ACETYLENES}

Among products from reactions of $\mathbf{1}$ or $\mathbf{2}$ with several acetylenes, those obtained from $\mathbf{2}$ and $\mathrm{ArC} \equiv \mathrm{CH}$ $\left(\mathrm{Ar}=\mathrm{C}_{6} \mathrm{H}_{5}, p-\mathrm{CH}_{3} \mathrm{C}_{6} \mathrm{H}_{4}\right)$ were characterizable by NMR spectroscopy. The X-ray structural analysis of the $p$-tolylacetylene analog (3) revealed the complex to have an acetylene dimer unit bridging over two $\mathrm{Pd}$ atoms (eq. 3) [5]. The terminal carbons can be regarded as bridging vinylidene ligands on the basis of the symmetric nature of the dinuclear unit and the following reactivity pattern. Thus, $\mathbf{3}$ rearranged, when dissolved in $\mathrm{CH}_{3} \mathrm{CN}$, to a complex containing a bridging P-ylide ligand (eq. 3) via nucleophilic attack of $\mathrm{PPh}_{3}$ at the bridging carbene carbon.

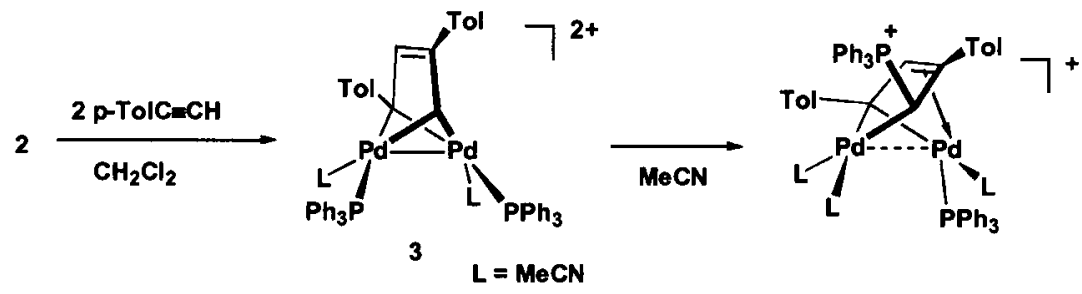

\section{REACTION OF 2 WITH 1,3-BUTADIENES}

The complex 2 reacted with 1,3-butadiene in $\mathrm{CH}_{2} \mathrm{Cl}_{2}$ to yield the sandwich type bis(butadiene) complex (4) in good yield (eq. 4). The striking structural aspect of 4, established crystallographically, was the extremely long Pd-Pd distance (3.19 $\AA$ ) for a $d^{9}-d^{9}$ combination [4]. Thus, the complex 4 can be regarded as an intermediate lying halfway on the reaction coordinate of $[2 \sigma+4 \pi]$ addition, though the observed geometry of the diene ligand was rather similar to those of the diene coordinating to the late transition metal fragments. The ab initio molecular orbital (MO) calculations on the model of $\mathbf{4}$ confirmed the important role of back donation interaction involving the filled $\mathrm{Pd}-\mathrm{Pd} \mathrm{d} \sigma-\mathrm{d} \sigma \mathrm{MO}$ and the empty diene $\pi^{*} \mathrm{MO}$ in stabilizing the Pd-Pd elongated structure.

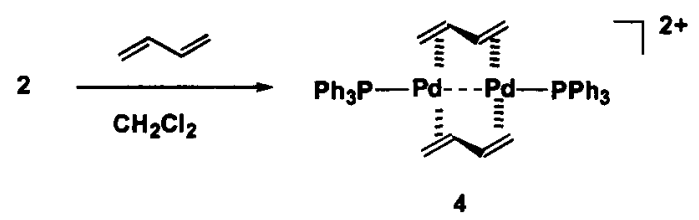

It should be noted that the above-mentioned elongation of the Pd-Pd bond takes place only when it is sandwiched by two diene ligands, since the Pd-Pd bond length (around $2.7 \AA$ ) bridged by only one 
diene ligand as in the complex 5 (prepared according to eq. 5) [3,6] lies in the range normal for the $\operatorname{Pd}(\mathrm{I})-\mathrm{Pd}(\mathrm{I})$ interaction.

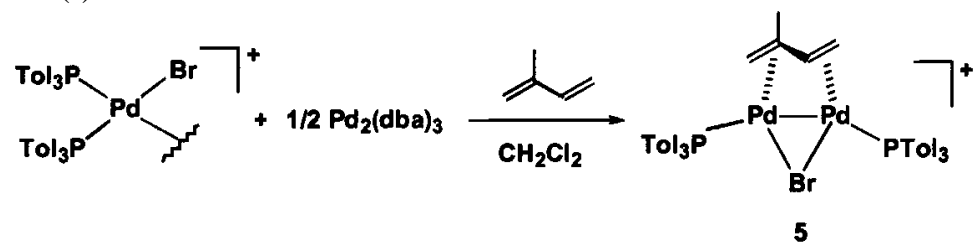

\section{REACTION OF 1 WITH CONJUGATED POLYENES}

During attempts of reacting $\mathbf{1}$ with some conjugated dienes or polyenes, it was established that $\mathbf{1}$ serves as a nice source of linear polypalladium chains that are sandwiched by two molecules of the polyene ligands [2]. Thus, for example, 1 reacted with 2 equiv of $\operatorname{Pd}(0)$ atoms $\left[\mathrm{Pd}_{2}\left(\mathrm{dba}_{3}\right.\right.$ is a source] in the presence of excess diphenyloctatetraene in $\mathrm{CH}_{2} \mathrm{Cl}_{2}$ to give the tetranuclear sandwich complex 6 in good yield (eq. 6). The complex 6 could alternatively be obtained from $\left[\mathrm{Pd}\left(\mathrm{CH}_{3} \mathrm{CN}\right)_{4}\right]^{2+}(1$ equiv) and $\operatorname{Pd}(0)$ (3 equiv) in the presence of the tetraene [7], but the former method was more convenient due to the easier purification procedure. The analogous linear polypalladium chain complexes $\left[\mathrm{Pd}_{\mathrm{n}}\left\{\mathrm{Ph}(\mathrm{CH}=\mathrm{CH})_{\mathrm{n}+1} \mathrm{Ph}\right\}_{2}\right]\left(\mathrm{BAr}_{\mathrm{f}}\right)_{2}\left(\mathrm{n}=3-6 ; \mathrm{BAr}_{\mathrm{f}}=\mathrm{B}\left\{\left(\mathrm{C}_{6} \mathrm{H}_{3}\left(\mathrm{CF}_{3}\right)_{2}\right\}_{4}\right)(7)\right.$ were prepared from 1 combined with the proper equivalents of $\operatorname{Pd}(0)$ and the appropriate polyene ligands. The structure of 6 is shown in Fig. 1, revealing $\eta^{3}: \eta^{2}: \eta^{2}: \eta^{3}$ coordination of the tetraene. The other remarkable aspects with this structure include 1) highly linear $\mathrm{Pd}_{4}$ skeleton with $\mathrm{Pd}-\mathrm{Pd}$ lengths being normal, and 2) almost planar polyene framework. The structure of $7(n=4)$, also determined crystallographically, is similar to that of $\mathbf{6}$ except that the former no more involves the coordination of the ipso and ortho carbons of the phenyl group.

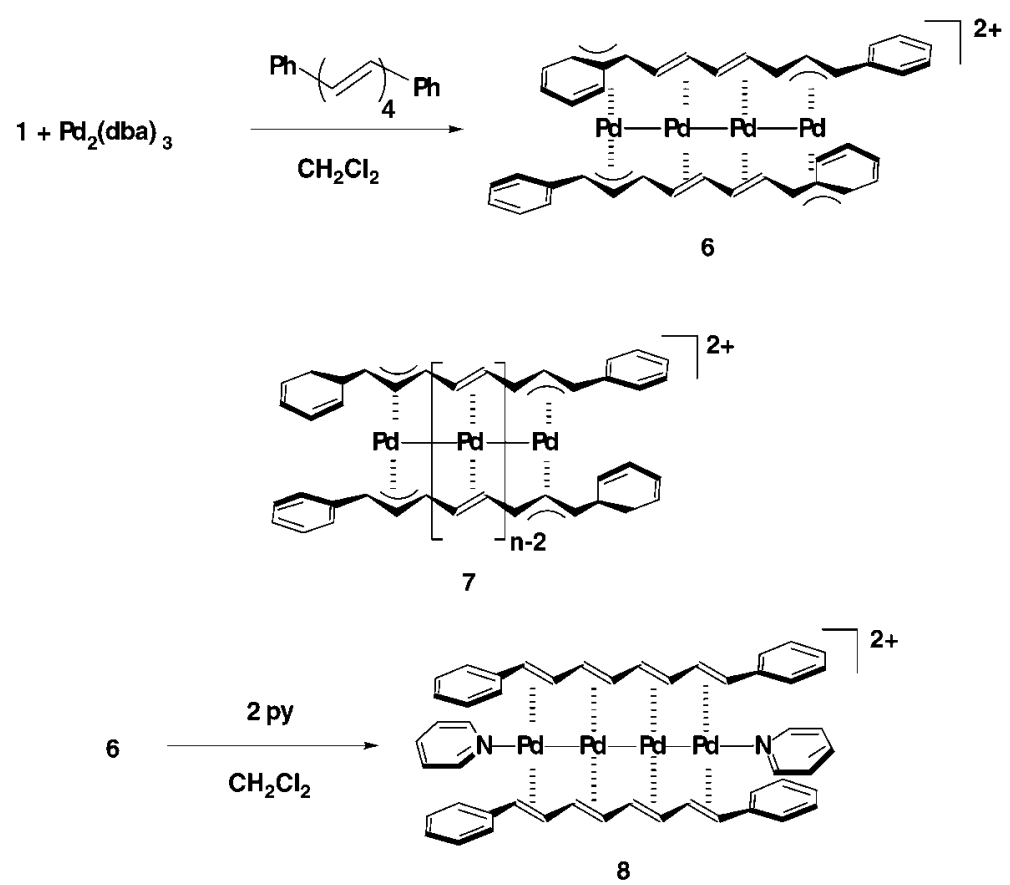

The mode of binding of the tetraene to $\mathrm{Pd}_{4}$ unit in 6 changed when this was reacted with pyridine, affording pyridine adduct $\mathbf{8}$ (eq. 7). The X-ray structure analysis of 8 confirmed the $\eta^{2}: \eta^{2}: \eta^{2}: \eta^{2}$ coordination of the tetraene ligand. 


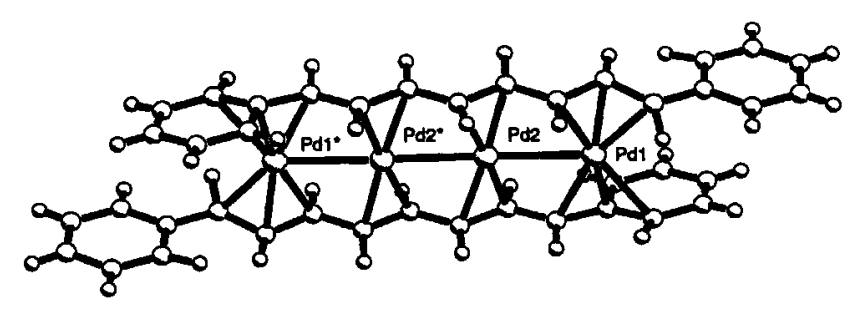

Fig. 1 Molecular structure of 6 (counter anion $\mathrm{BAr}_{\mathrm{f}}^{-}$).

\section{REFERENCES}

1. R. R. Thomas and A. Sen. Inorg. Synth. 28, 63 (1990).

2. T. Murahashi, T. Nagai, T. Okuno, T. Matsutani, H. Kurosawa. J. Chem. Soc. Chem. Comm. 1689 (2000).

3. T. Murahashi. Dissertation, Dr. Engineering, Osaka University, 1999.

4. T. Murahashi, T. Otani, E. Mochizuki, Y. Kai, H. Kurosawa, S. Sakaki. J. Am. Chem. Soc. 120, 4563 (1998).

5. T. Murahashi, T. Otani, T. Okuno, H. Kurosawa. Angew. Chem. Int. Ed. 39, 537 (2000).

6. T. Murahashi, N. Kanehisa, Y. Kai, T. Otani, H. Kurosawa. J. Chem. Soc. Chem. Comm. 825 (1996).

7. T. Murahashi, E. Mochizuki, Y. Kai, H. Kurosawa. J. Am. Chem. Soc. 121, 10660 (1999). 